\title{
Editorial
}

\section{Primary Health Care Research and Development and the Society for Academic Primary Care: a marriage made in heaven?}

This issue marks the first step in the collaboration between Primary Health Care Research and Development and the Society for Academic Primary Care (SAPC). The Society aims to promote excellence in research, education and policy development in general practice and primary health care. It has a multidisciplinary membership of over 700 individuals working in academic primary care, $40 \%$ of whom are from non-medical backgrounds. The journal has provided a forum for its transdisciplinary community to publish peer-reviewed, high-quality international interdisciplinary research focused on primary care since 2000. An alliance seems long overdue.

For the last 18 months, we have been in discussion with the journal editors and the publisher, Cambridge University Press, to create a collaboration that is mutually beneficial but which, above all, is greater than the sum of its parts. We recognised that the regular readership of this journal, some of whom will also be members of SAPC, are engaged in all aspects of often complex and messy community-based work as practitioners and/or researchers. We are all interested in improving health, and equity in health, through working within a first contact service located close to patients' homes (Roland and Wilkin, 1996). The journal's stated aim is to bridge the gap between research and practice. This collaboration, will, we hope, further encourage researchers and practitioners to do this by working together more closely, improving the relevance and quality of our research for the benefit of patients and their communities.

So, why should an academic society need a journal and a journal need an association with a learned society? Primary care, in its broadest (C) 2008 Cambridge University Press sense, has made considerable advances in its research capacity and productivity over the last 40 years. Peer-reviewed journals play a unique and respected role in showcasing high-quality research. Primary care-oriented journals help to develop and disseminate an integrated body of knowledge grounded in science, practice and different ways of knowing, which are relevant to the generalist paradigm (Stange et al., 2001). Primary Health Care Research and Development is one such forum. The numbers of journals that prioritise primary care research is relatively small, and it is an important opportunity for members to widen their publishing options by becoming more familiar with this journal.

Reciprocally, researchers can help to improve the prominence of a journal through submitting the work they feel is of value and which represents their best endeavours. This may, in turn, improve the journal's 'impact factor.' The USbased Annals of Family Medicine, first published in Spring 2003, has recently announced its inaugural impact factor of 3.8 , which is a tribute to the hard work of both its visionary editors and contributors. To the uninitiated, the system of awarding an impact factor can seem as complex and mystical as the offside rule. It has achieved prominence, indeed notoriety, as a means of differentiating between the approximately 16000 scientific journals currently in existence, of which around 4000 have an impact factor (Mabe, 2003). At its most simplistic, the impact factor is the average number of times articles from the journal published in the past two years have been cited in the current year. It is, however, a far-from-perfect tool for assessing journal quality, influenced by the number of review articles published, biased 
towards English language articles and unable to differentiate between positive or negative citations (Seglen, 1997). Nevertheless, it is part of the currency of academe and continues to carry weight with those wishing to publish their work in a prestigious journal. Primary Health Care Research and Development is already well on its way to achieving an impact factor. It would be added value for all concerned if this collaboration helped move this forward.

The other benefit of an academic association between a membership organisation and a journal is the opportunity for mutual representation at scientific meetings and on editorial boards. We hope that the wider readership of Primary Health Care Research and Development will be interested in SAPC, and that SAPC members will extend their experience of the academic publishing world through the expertise of the journal's editors and their contributions at our meetings. We are confident that this collaboration will extend and illuminate the frontier of academic primary care. We hope and expect it to catalyse progress in the field of primary care research, at a time of great change and opportunity for the research community.
Helen Lester

Professor of Primary Care \& Secretary of SAPC $N P C R D C$ 5th Floor, Williamson Building, Oxford Road Manchester, M13 9PL

Amanda Howe

Professor of Primary Care \& Chair of SAPC MEDI Building

School of Medicine, Health Policy and Practice Institute of Health University of East Anglia Norwich, NR4 7TJ, Norfolk

\section{References}

Mabe, M. 2003: The growth and number of journals. Serials 16, 191-97.

Roland, M. and Wilkin, D. 1996: Rationale for moving towards a primary care-led NHS. In National Primary Care Research and Development Centre. What is the future for a primary care-led NHS? Oxford: Radcliffe Medical Press, 5-12.

Seglen, O. 1997: Why the impact factor of journals should not be used for evaluating research. British Medical Journal 314, 498-502.

Stange, K., Miller, W.I. and McWhinney, I. 2001: Developing the knowledge base of family practice. Family Medicine 33, 286-89. 